\title{
Understanding the natural variation in heat stress response in Pigeonpea and crop wild relatives through time-series transcriptome analysis
}

\author{
Ramakrishna G. ${ }^{1}$, Parampreet Kaur ${ }^{2}$, Anupam Singh ${ }^{1}$, Sunishtha Yadav ${ }^{3}$, Sandhya \\ Sharma ${ }^{1}$, Nagendra Singh ${ }^{1}$, and Kishor Gaikwad ${ }^{4}$ \\ ${ }^{1}$ ICAR-National Institute for Plant Biotechnology \\ ${ }^{2}$ Punjab Agricultural University \\ ${ }^{3}$ Amity University Amity Institute of Biotechnology \\ ${ }^{4}$ Affiliation not available
}

June 23, 2020

\begin{abstract}
As the temperatures are projected to increase across the world due to global warming, heat stress (HS) is a major concern for all crop plants. We report here, a time-series transcriptome analysis of one Pigeonpea cultivar (Cajanus cajan) and two Crop Wild Relatives (CWRs), Cajanus acutifolius and Cajanus scarabaeoides under heat stress (HS) at $42 \pm 2^{\circ}$ C. A total of 9521,12447 , 5282 transcripts were identified to be differentially expressed in C. cajan, C. acutifolius and C. scarabaeoides respectively. In this study, we also examined alternative splicing (AS) during HS and revealed that a significant number of DEGs undergo AS in a species-specific pattern. Both transcriptome and qRT-PCR analysis showed that the HS caused the down-regulation of photosynthetically important genes such as Curvature Thylakoid protein, RuBisCO small chain, and NDH complex subunit; fatty acid modulating genes and up-regulation of defense mechanisms such as expression of HSPs and anti-oxidant enzymes in all Cajanus species. The results of histochemical assay showed higher lipid peroxidation in C. acutifolius inferring the presence of high quantity of PUFA in the plasma membrane which might have led to severe damage of membrane-bound organelles like chloroplast during HS, coupled by high electrolyte leakage during HS.
\end{abstract}

\section{Hosted file}

Pigeonpea_HS transcriptome.doc available at https://authorea.com/users/336233/articles/ 461955-understanding-the-natural-variation-in-heat-stress-response-in-pigeonpea-andcrop-wild-relatives-through-time-series-transcriptome-analysis

\section{Hosted file}

Figures.pptx available at https://authorea.com/users/336233/articles/461955-understandingthe-natural-variation-in-heat-stress-response-in-pigeonpea-and-crop-wild-relativesthrough-time-series-transcriptome-analysis 